\title{
Simple filter microchip for rapid separation of plasma and viruses from whole blood
}

This article was published in the following Dove Press journal:

International Journal of Nanomedicine

14 September 2012

Number of times this article has been viewed

\section{ShuQi Wang' \\ Dusan Sarenac' \\ Michael H Chen' \\ Shih-Han Huang' \\ Francoise F Giguel ${ }^{2}$ \\ Daniel R Kuritzkes ${ }^{3}$ \\ Utkan Demirci ${ }^{1,4}$}

'Bio-acoustic MEMS in Medicine Laboratory, Department of Medicine, Division of Biomedical Engineering, Brigham and Women's Hospital, Harvard Medical School, Boston, MA, USA; ${ }^{2}$ Infectious Diseases Unit, Massachusetts General Hospital, Boston, MA, USA; ${ }^{3}$ Section of Retroviral Therapeutics, Brigham and Women's Hospital, Boston, MA, USA ${ }^{4}$ Harvard-MIT Health Sciences and Technology, Cambridge, MA, USA

Correspondence: Utkan Demirci Harvard-MIT Health Sciences and Technology, Bio-Acoustic MEMS in Medicine (BAMM) Laboratories, 65 Landsdowne Street, Cambridge 02139, MA, USA

Tel +l 6509069227

Email udemirci@rics.bwh.harvard.edu

\begin{abstract}
Sample preparation is a significant challenge for detection and sensing technologies, since the presence of blood cells can interfere with the accuracy and reliability of virus detection at the nanoscale for point-of-care testing. To the best of our knowledge, there is not an existing on-chip virus isolation technology that does not use complex fluidic pumps. Here, we presented a lab-on-a-chip filter device to isolate plasma and viruses from unprocessed whole blood based on size exclusion without using a micropump. We demonstrated that viruses (eg, HIV) can be separated on a filter-based chip (2- $\mu \mathrm{m}$ pore size) from HIV-spiked whole blood at high recovery efficiencies of $89.9 \% \pm 5.0 \%, 80.5 \% \pm 4.3 \%$, and $78.2 \% \pm 3.8 \%$, for viral loads of $1000,10,000$ and 100,000 copies $/ \mathrm{mL}$, respectively. Meanwhile, $81.7 \% \pm 6.7 \%$ of red blood cells and $89.5 \% \pm 2.4 \%$ of white blood cells were retained on $2 \mu \mathrm{m}$ pore-sized filter microchips. We also tested these filter microchips with seven HIV-infected patient samples and observed recovery efficiencies ranging from $73.1 \% \pm 8.3 \%$ to $82.5 \% \pm 4.1 \%$. These results are first steps towards developing disposable point-of-care diagnostics and monitoring devices for resource-constrained settings, as well as hospital and primary care settings.
\end{abstract}

Keywords: microchip, filtration, virus isolation, plasma separation, point-of-care

\section{Introduction}

Pandemic diseases including HIV, malaria, and TB, as well as emerging infectious diseases such as influenza H1N1 have raised serious challenges for global health and homeland security. For instance, HIV has caused more than 25 million deaths since the first reported case of AIDS in 1981, and currently there are approximately 33.3 million people living with HIV. ${ }^{1}$ Emerging endemics present grand threats to the public health. For example, H1N1 rapidly spread worldwide and caused a global pandemic in $2009,{ }^{2,3}$ and a similar strain led to over 50 million deaths in $1918 .^{3}$ To prevent and control these highly contagious infectious diseases, there is a need for implementing rapid and simple diagnostic technologies to detect early cases in the field. As such, microfluidic systems, due to their portability, affordability, and high sensitivity, have become promising technologies to develop point-of-care (POC) diagnostics. ${ }^{4-7}$

Currently, POC diagnostics require on-chip sample processing, including plasma separation from whole blood as an initial step. ${ }^{8,9}$ For example, inclusion of blood cells or components such as hemoglobin and lactoferrin may inhibit DNA polymerase in polymerase chain reaction (PCR) analysis and lead to inaccurate quantification or even amplification failure. ${ }^{10}$ Similarly, inhibitors from whole blood can interfere with enzyme-linked immunosorbent assay (ELISA) and result in low sensitivity and specificity. ${ }^{11,12}$ In addition, reducing the concentration of cellular components of blood, 
and separating viruses in plasma using a rapid system may increase the capture efficiency microfluidic-based viral detection platforms. ${ }^{13,14}$ This is particularly important for optical sensors, since the presence of blood cells in the sample can negatively affect the optical detection path and compromise accuracy. Detection technologies such as whispering gallerymode devices, ${ }^{15}$ plasmon resonance devices, ${ }^{16}$ and photonic crystals, ${ }^{17}$ can benefit from the preremoval of nontargeted cells from whole blood to enhance the capture efficiency of targeted pathogens and proteins. In a clinical laboratory setting, plasma separation can simply be performed by centrifugation, whereas it remains a challenge at the POC, especially in resource-constrained settings due to lack of laboratory infrastructure. ${ }^{18-20}$ Hence, simple, inexpensive, and rapid plasma separation on-chip is urgently needed to facilitate POC diagnosis.

There have been microfluidic approaches to achieve onchip plasma separation via driving forces such as centrifugal force, ${ }^{21,22}$ capillary force, ${ }^{23}$ and the Zweifach-Fung effect. ${ }^{24}$ However, these approaches have inherent shortcomings that render them not suitable for POC testing. For example, centrifugation-based compact-disk chips require electricity for high-speed rotation. ${ }^{21,22}$ Although capillary forces can be utilized to extract plasma to remove the need for electricity, small volumes of plasma can be extracted (a few nanoliters to microliters), ${ }^{25}$ which may be insufficient for conventional detection methods such as PCR or ELISA. To improve the yield, a continuous cross-flow device was designed to separate blood cells in microchannels at high flow rates. ${ }^{24}$ Despite enhanced plasma yields, this device requires accurate flow rates and a long fractionation time, which may not be ideal to achieve rapid detection of infectious agents at resource-constrained settings. Recently, plasma separation on-chip can also be achieved using a $\mathrm{H}_{2} \mathrm{O}_{2}$-powered pump ${ }^{26}$ or degas-driven flow in evacuated polydimethylsiloxane devices. ${ }^{25}$ However, the demanding storage conditions for $\mathrm{H}_{2} \mathrm{O}_{2}$ or vacuum limits the shelf life of these devices. Thus there is an unmet need to develop simple, robust sample-processing devices that can achieve rapid plasma separation to facilitate POC testing. ${ }^{27}$

Microfilters with pore sizes ranging from 5 to $30 \mu \mathrm{m}$ have been used to isolate plasma from whole blood;28 however, these approaches focus on cells. In contrast, we demonstrated isolation of viruses using small pore sizes (1-2 $\mu \mathrm{m})$, which has not yet been reported. We separated viruses, which were $110-146 \mathrm{~nm}$ in size, ${ }^{29}$ from whole blood using a microchip with 1-2 $\mu \mathrm{m}$ diameter porous filter membranes, which can be used as a preliminary on-chip step to detect viruses from whole blood by immunocapture. ${ }^{13,14}$ We used HIV as a relevant virus model, and validated this microchip using hematological analysis and reverse transcription quantitative PCR (RT-qPCR). The presented work is the first demonstration of a simple, rapid, pump-free, antibody-free pathogen isolation device, which can reliably recover infectious agents using size-based separation from unprocessed whole blood. The presented microchip has broad potential applications; for instance, it can be coupled with existing battery-operated diagnostic tools, or integrated with microchip ELISA or PCR as a sample preparation module for POC testing.

\section{Materials and methods Device fabrication}

The device consisted of four layers of poly(methyl methacrylate) (PMMA) (McMaster-Carr, Atlanta, GA) and four layers of double-sided adhesive (DSA) (iTapestore, Scotch Plains, $\mathrm{NJ}$ ), and a filter membrane (Figure 1A). The device was fabricated utilizing a laser cutter, as previously described. ${ }^{4,7,14,30,31}$ The device had outer dimensions of $25 \times 40 \mathrm{~mm}$. PMMA and DSA layer thicknesses were $1.5 \mathrm{~mm}$ and $50 \mu \mathrm{m}$, respectively. There was a circular opening with a diameter of $800 \mu \mathrm{m}$ on the first PMMA layer to allow for blood injection into the inlet chamber. On this layer of PMMA, there was a rectangular opening $\left(7.7 \times 8.1 \mathrm{~mm}^{2}\right)$ to collect plasma at the outlet chamber. The second PMMA layer had two separate rectangular openings $\left(7.7 \times 8.1 \mathrm{~mm}^{2}\right)$. Underneath the second PMMA layer was a Whatman nuclepore polycarbonate track-etched membrane with low protein-binding capacity (Fisher Scientific, Pittsburgh, PA), and pore sizes ranging from 0.4 to $3 \mu \mathrm{m}$ in diameter. The third PMMA layer contained two rectangular openings, which were connected by a channel $\left(1.7 \times 7.8 \times 1.5 \mathrm{~mm}^{3}\right)$. The fourth PMMA layer had no openings. These four PMMA layers and one layer of filter membrane were assembled via four layers of DSA (50 $\mu \mathrm{m}$ in thickness). Once assembled, the filter device had two rectangular chambers $(100 \mu \mathrm{L})$ above and below the filter membrane (Figure 1B). The rectangular chamber under the filter membrane was connected to the outlet chamber by a microfluidic channel.

\section{Device operation}

To investigate the microchip performance, we evaluated the device operation in a range of flow rates using a micropump. After we validated the chip operation using a flow-controlled system, we utilized manual flow 

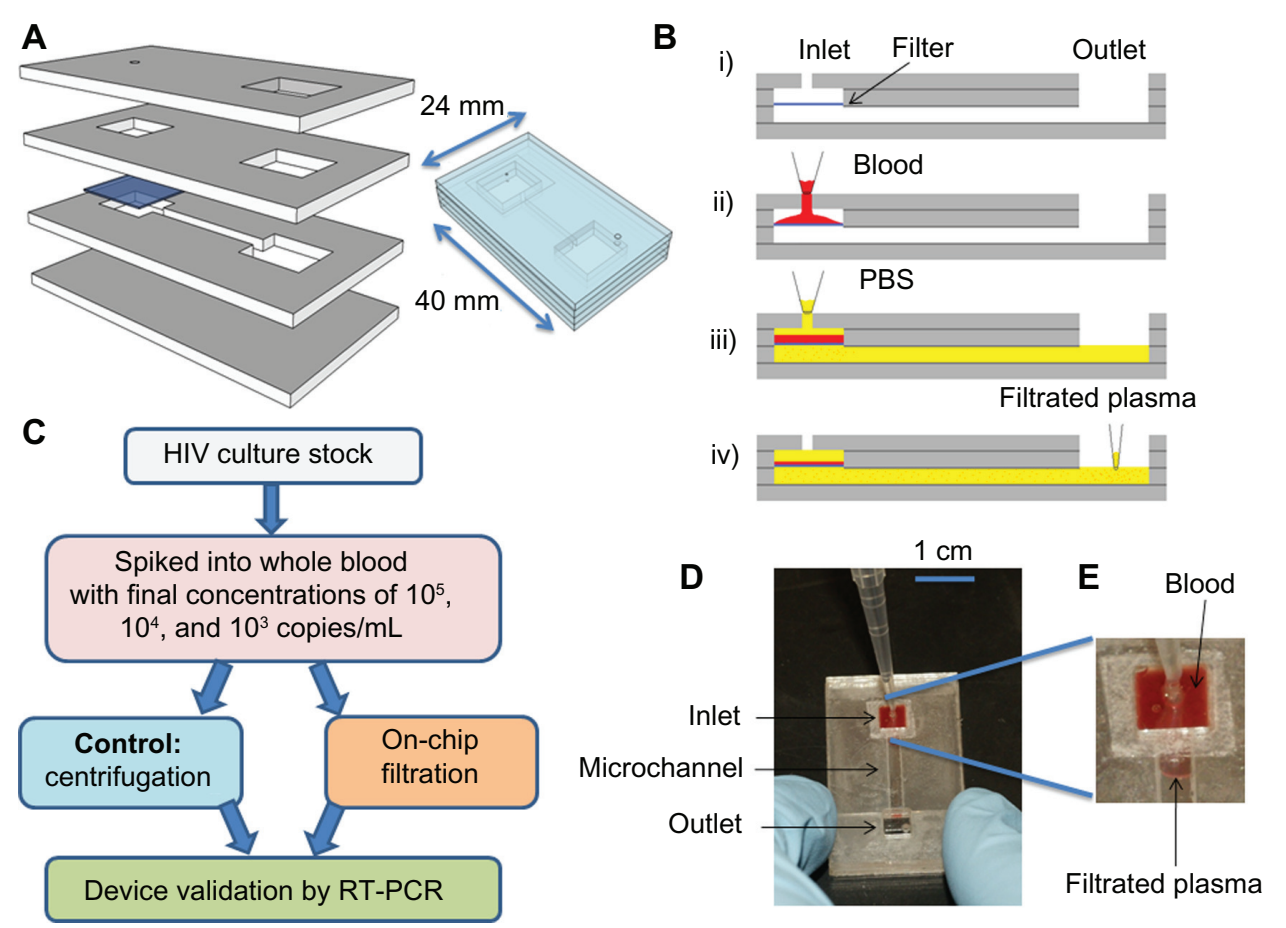

Figure I (A-E) Design of the size-based filter microchip. (A) Assembly of a size-based filter microchip; (B) functionality of the size-exclusion-based filter microchip (i) crosssection of the assembled device, (ii) injection of blood into the inlet through a pipette, (iii) injection of PBS into the inlet chamber to wash platelets and plasma through the microchannel and into the output channel, (iv) collection of plasma from the outlet; (C) the experimental chart for validation of virus recovery using filter microchips; (D) the device during filtration; (E) close-up of the plasma separated by the filter membrane.

Abbreviations: PBS, phosphate-buffered saline; RT-PCR, reverse transcriptase-polymerase chain reaction.

for virus separation by pipetting, eliminating the need for a micropump. The filtration process included injection of blood and continuous wash with phosphate-buffered saline (PBS, pH 7.4). First, $40 \mu \mathrm{L}$ of de-identified whole blood purchased from Blood Research Component (Cambridge, MA) was injected into the inlet chamber using a micropump (Programmable Syringe Pump, Sarasota, FL). Next, a minimum of $200 \mu \mathrm{L}$ of PBS was injected using a micropump at flow rates of 100, 200, 300, 400, and $500 \mu \mathrm{L} / \mathrm{min}$. These flow rates covered a broad flow-rate range before evaluating manual pipetting. The injection of PBS allowed the solution in the inlet chamber to replenish as separated plasma was pushed out from the outlet chamber (Figure 1D). Red blood cells (RBCs) and white blood cells (WBCs) were retained by the filter membrane, since their sizes exceed the pore size of the filter membrane. The injected PBS volume used in this study varied from 200 to $500 \mu \mathrm{L}$ so that the inlet chamber could be completely washed. Following the wash, plasma was collected from the outlet chamber using a syringe with a tubing with an inner diameter of $0.05 \mathrm{~cm}$ (VWR Scientific, West Chester, PA) attached. The tubing was pushed from the outlet through the channel to the chamber under the membrane. This approach maximized the collection volume, and the volume of collected plasma was measured using a pipette.

For virus isolation from whole blood, we did not use a syringe pump. We manually introduced HIV-spiked whole blood samples into the microchip using a pipette. HIV subtype $\mathrm{C}$ intact particles were isolated from a clinical sample and co-cultured in peripheral blood mononuclear cells using a standard protocol. HIV particles were recovered using the (1 and $2 \mu \mathrm{m}$ filter membranes) microchip and compared to centrifugation at $1000 \mathrm{~g}$ for 10 minutes (chart as shown in Figure 1C). Forty $\mu \mathrm{L}$ of blood sample was spiked with cultured HIV viruses (with final concentrations of $10^{5}, 10^{4}$, and $10^{3}$ copies $/ \mathrm{mL}$ ). The spiked samples were loaded into the microchip using a pipette and manually washed with $300 \mu \mathrm{L}$ of PBS using a manual pipette. The filtration process took approximately 1 minute to complete.

\section{Hematological analysis}

D3 Hematology Analyzer (Drew Scientific, Dallas, TX) was used for hematological analysis. The machine was calibrated and maintained according to the manufacturer's instructions. For hematological analysis, $10 \mu \mathrm{L}$ of blood sample or plasma filtrate was analyzed to measure the concentration 
of blood components, ie, RBCs, WBCs, and platelets. The passage rate was calculated as follows:

$$
\begin{aligned}
& \text { Passage rate }(\%) \\
& =\frac{\text { Concentration }_{\text {filtrate }} \times \text { Volume of filtrate }}{\text { Concentration }_{\text {blood }} \times \text { Volume of input blood }} \times 100
\end{aligned}
$$

where concentration $_{\text {filtrate }}$ is the concentration of WBCs, $\mathrm{RBCs}$, and platelets in the filtrate, and concentration blood $_{\text {is }}$ the concentration of WBCs, RBCs, and platelets in blood before filtration.

\section{Quantification of HIV by RT-qPCR}

Plasma filtrate containing HIV subtype $\mathrm{C}$ was quantified using RT-qPCR. ${ }^{32}$ HIV-1 RNA was first extracted using the QIAamp Viral RNA Mini Kit (Qiagen, Valencia, CA) according to the manufacturer's instructions. In the $\mathrm{RT}$ reaction $(20 \mu \mathrm{L})$, the master mixture contained $10 \mu \mathrm{L}$ of $2 \times$ core RT buffer, $2 \mu \mathrm{L}$ of $10 \mu \mathrm{M}$ of reverse primer LTR-R2 (5'GTCTGAGGGATCTCTCTAGTTACCAG-3'), $0.5 \mu \mathrm{L}$ of AffinityScript (Applied Biosystems, Carlsbad, CA), and $7.5 \mu \mathrm{L}$ of HIV-1 RNA. The RT reaction was carried out at $25^{\circ} \mathrm{C}$ for 5 minutes, $45^{\circ} \mathrm{C}$ for 60 minutes, and $95^{\circ} \mathrm{C}$ for 3 minutes, on the GeneAmp PCR System 9700 (Applied Biosystems). In the following qPCR $(50 \mu \mathrm{L})$, the master mixture consisted of $1 \times$ core PCR buffer, $0.4 \mu \mathrm{M}$ of forward primer LTR-F (5'-TAAAGCTTGCCTTGAGTGCT-3') and reverse primer LTR-R2, $0.2 \mu \mathrm{M}$ of TaqMan probe LTR-P (JOE as the fluorophore and TAMRA as the quencher), $2.5 \mathrm{U}$ of SureStart Taq polymerase, and $10 \mu \mathrm{L}$ of cDNA template. The amplification reaction was carried out at $25^{\circ} \mathrm{C}$ for 5 minutes and then at $95^{\circ} \mathrm{C}$ for 10 minutes, and it was followed by 50 two-step cycles of $60^{\circ} \mathrm{C}$ for 1 minute and $95^{\circ} \mathrm{C}$ for 30 seconds on the 7300 Real-Time PCR System (Applied Biosystems). In addition, seven discarded and de-identified HIV-infected whole blood samples were collected from Massachusetts General Hospital with the approval of the Institutional Review Board (protocol: 2009P000749). These patient samples were processed on-chip as the spiked samples described above. The recovery of HIV was determined by the following formula, in which the parameter of volume was omitted since the sample volume of ultracentrifugation and microchip separation was adjusted in RNA extraction.

Recovery (\%)

$$
=\frac{\text { HIV viral load in the filtrate sample }}{\text { HIV viral load in the centrifugation sample (control) }} \times 100 \%
$$

The sample volume processed in centrifugation was adjusted to $40 \mu \mathrm{L}$, which was equivalent to the sample volume processed on-chip.

\section{Results and discussion}

In this study, we developed an on-chip filtration method based on size exclusion, characterized the filter device for plasma filtration from various aspects including pore size, flow rate, and wash volume, and finally applied it to HIV isolation from unprocessed whole blood. Blood components have different sizes; the average diameters of RBCs, WBCs, and platelets are 6-8 $\mu \mathrm{m}, 6-20 \mu \mathrm{m}$ (depending on the cell types, including basophils, eosinophils, lymphocytes, monocytes, and neutrophils), and $1.5-3.5 \mu \mathrm{m},{ }^{33}$ respectively. Thus, we used four different filters with varying pore sizes $(0.4,1,2$ and $3 \mu \mathrm{m}$ ) to explore the capability of a filter membrane assembled in a microfluidic device to separate plasma, which is often used as a standard sample type for clinical diagnosis (eg, HIV viral load measurement). Also, we evaluated the effects of flow rate and wash volume on passage rates of blood components so as to minimize their presence in the filtrate. Lastly, we investigated the on-chip recovery of HIV particles, which have diameters ranging from 110 to $146 \mathrm{~nm},{ }^{29}$ from whole blood spiked with HIV or from HIV-infected patient blood samples.

We evaluated the effect of pore size on plasma separation using four filter membranes of different pore sizes $(0.4,1,2$, and $3 \mu \mathrm{m})$ and measured the passage rates of blood components. For the pore sizes ranging from 0.4 to $3 \mu \mathrm{m}$, WBC concentrations in the filtrate were below $0.3 \times 10^{3} /$ $\mu \mathrm{L}$, compared to $6.5 \times 10^{3} / \mu \mathrm{L}$ in whole blood (Figure $2 \mathrm{~A}$ ); the $\mathrm{RBC}$ concentrations in the filtrate were less than $0.45 \times$ $10^{6} / \mu \mathrm{L}$, compared to $5.0 \times 10^{6} / \mu \mathrm{L}$ in whole blood (Figure $2 \mathrm{~B}$ ); and the platelet concentrations in the filtrate were below $28.5 \times 10^{3} / \mu \mathrm{L}$, compared to $203.7 \times 10^{3} / \mu \mathrm{L}$ in whole blood (Figure 2C). The size constraint by the filter was also reflected in the passage rates of these blood components in the filtrate (Figure 2D). For the pore size of $0.4 \mu \mathrm{m}$, the passage rates of WBCs, RBCs, and platelets were below $2.1 \%$, indicating that these blood components can be separated from plasma by size exclusion-based filter microchips (Figure 2D). It was also observed that by using a $3 \mu \mathrm{m}$ pore size microchip, a considerable amount of WBCs and RBCs passed through the filters, with the passage rate increasing to $25.1 \%$ and $49.7 \%$, respectively. The passage rates of platelets were $47.7 \%, 67.7 \%$, and $74.6 \%$, using microchips with pore sizes of 1,2 , and $3 \mu \mathrm{m}$, respectively. These results indicated that 
A

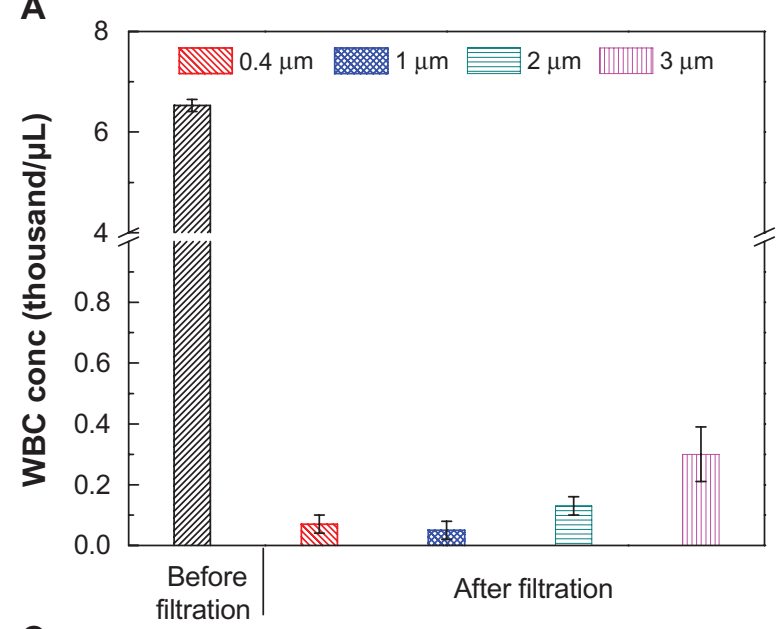

\section{。}

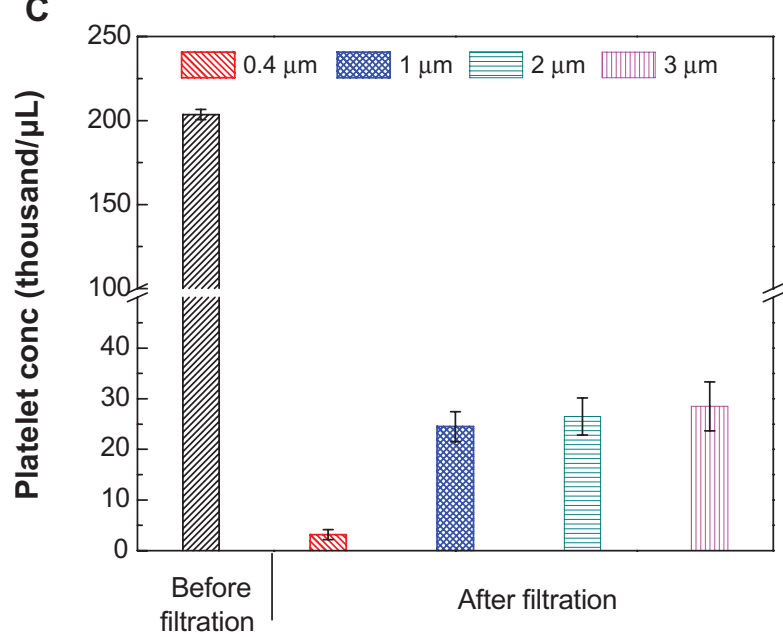

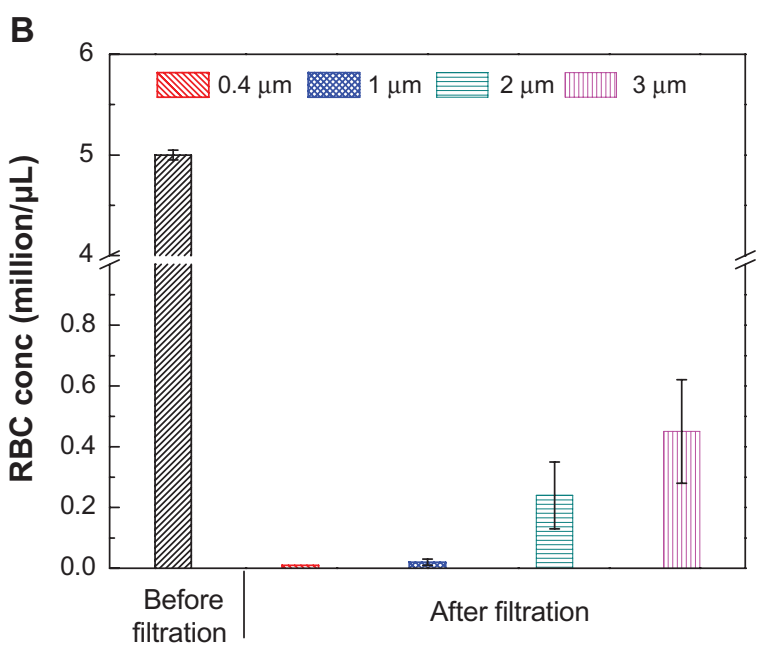

D

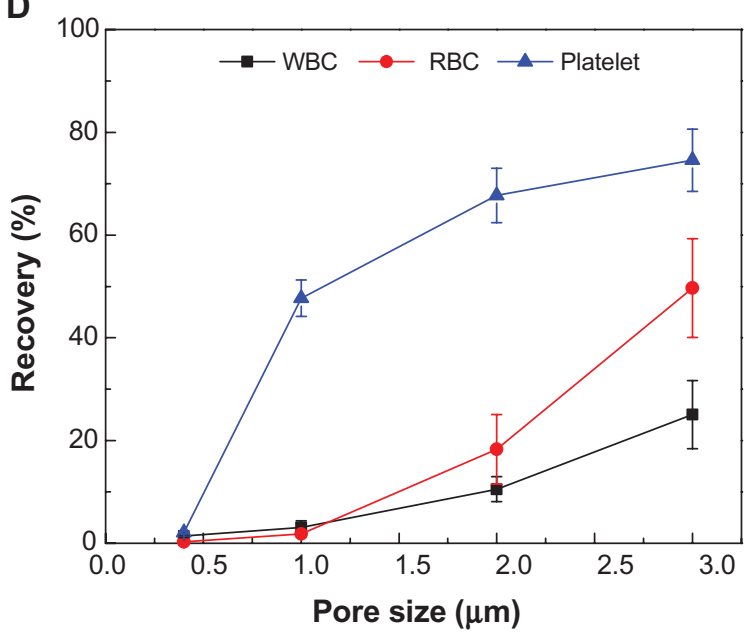

Figure 2 (A-D) Comparison of 0.4, I, 2 and $3 \mu \mathrm{m}$ pore-sized membranes for blood component filtration. In this experiment, $40 \mu \mathrm{L}$ of blood was injected into the inlet chamber, and it was subsequently injected with $300 \mu \mathrm{L}$ of phosphate-buffered saline. To evaluate the separation process, a micropump was used and the flow rate was $300 \mu \mathrm{L} / \mathrm{min}$. The collected filtrate volumes were $55 \pm 6$, I59 $\pm 10,197 \pm 8$, and $220 \pm 5 \mu \mathrm{L}$ for $0.4, \mathrm{I}, 2$ and $3 \mu \mathrm{m}$ pore-sized filters, respectively. (A) The concentration of RBCs before and after filtration. (B) The concentration of platelets before and after filtration. (C) The concentration of WBCs before and after filtration. (D) Summary of the passage rate of blood components on-chip.

Note: Data are presented as average \pm standard error $(n=6)$.

Abbreviations: WBCs, white blood cells; RBCs, red blood cells.

larger pore sizes allowed more cells and platelets to pass through the filter microchip. It should be noted that $0.4 \mu \mathrm{m}$ filters clogged rapidly since the collected volume of filtrate was $55 \pm 6 \mu \mathrm{L}$. The collected filtrate volumes were $159 \pm 10$, $197 \pm 8$, and $220 \pm 5 \mu \mathrm{L}$ for 1,2 and $3 \mu \mathrm{m}$ diameter filters, respectively. Thus, we selected the $2 \mu \mathrm{m}$ pore-sized filter for further evaluation, as it represented the best balance between high selectivity and high filtrate yield.

Secondly, we evaluated the effect of wash volume on plasma separation using PBS. For a filter size of $2 \mu \mathrm{m}$, the collected volumes at the outlet were $103 \pm 6,202 \pm 14$, $307 \pm 6$, and $403 \pm 15 \mu \mathrm{L}$ for wash volumes of 200,300 , 400 , and $500 \mu \mathrm{L}$, respectively. The passage rates of WBCs, RBCs, and platelets increased as more wash buffer passed through a filter (Figure 3). For example, the passage rate of platelets increased from $30 \%$ to $76 \%$ when the wash volume increased from 200 to $500 \mu \mathrm{L}$. For WBCs, the passage rate remained at approximately $10 \%$ for the wash volumes of 300,400 , and $500 \mu \mathrm{L}$. In comparison, the passage rates of RBCs were $19.1 \% \pm 2.4 \%, 19.7 \% \pm 2.6 \%$, and $29.0 \% \pm 3.1 \%$ for the wash volumes of 300,400 , and $500 \mu \mathrm{L}$, respectively. It was observed that the average passage rate of RBCs $(22.6 \% \pm 5.0 \%)$ was higher than that of WBCs $(10.8 \% \pm 2.2 \%)$ when the wash volume was larger (300-500 $\mu \mathrm{L}$ ). These results indicated that larger wash buffer could pass more platelets and RBCs through the filter microchip, which may be due to the deformability of RBCs. ${ }^{34}$ Thus, we chose a wash volume of $300 \mu \mathrm{L}$ for the following 


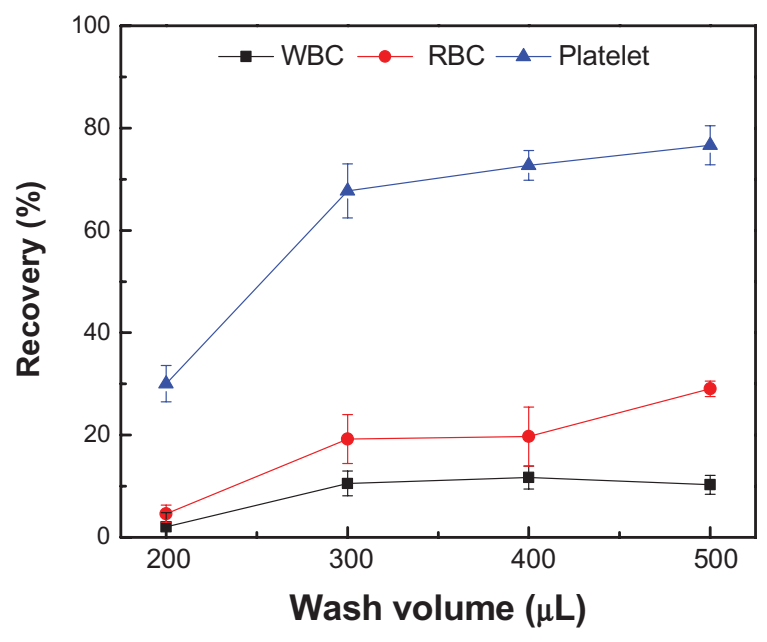

Figure 3 Passage rates of blood components on-chip with different volumes of wash buffer.

Notes: $40 \mu \mathrm{L}$ of blood was injected into the device with a pore size of $2 \mu \mathrm{m}$. Subsequently, the device was injected with $200,300,400$, and $500 \mu \mathrm{L}$ of phosphatebuffered saline. To evaluate the separation process, a micropump was used and the flow rate was $300 \mu \mathrm{L} / \mathrm{min}$. The collected filtrate volumes were $103 \pm 6$, $202 \pm 14,307 \pm 6$, and $403 \pm 15 \mu \mathrm{L}$, for wash volumes of $200,300,400$, and $500 \mu \mathrm{L}$, respectively. Data are presented as average \pm standard error $(n=6)$.

experiments to maximize the analyte yield and minimize the number of blood cells passing through the filter.

Third, we evaluated the effect of flow rate on the passage rate of blood components, in which a micropump was used to set a flow rate ranging from 100 to $500 \mu \mathrm{L}$ /minute (Figure 4). Although the device was designed to be operated by manual flow, we evaluated the filtration performance using a flow pump to set up flow rates within the range that manual pipetting may vary. We observed that the concentrations of WBCs in the filtrate remained below $0.2 \times 10^{3} / \mu \mathrm{L}$ (Figure $4 \mathrm{~A}$ ). In comparison, the concentrations of $\mathrm{RBCs}$ increased from $0.11 \times 10^{6}$ cells $/ \mu \mathrm{L}$ to $0.22 \times 10^{6}$ cells $/ \mu \mathrm{L}$, as the flow rate increased from 100 to $500 \mu \mathrm{L} /$ minute (Figure 4B). Under these flow rates, the platelet concentration in the filtrate increased from 24.3 to $27.7 \times 10^{3} / \mu \mathrm{L}$ (Figure $4 \mathrm{C}$ ). The passage rates of blood components at different flow rates are shown in Figure 4D. The passage rates of WBCs and platelets were not significantly affected by flow rates, with an average passage rate of $10.8 \% \pm 1.6 \%$, and $65.8 \% \pm 1.9 \%$, respectively. There was an increase in the passage rate of RBCs from $11.5 \% \pm 5.7 \%$ to $25.2 \% \pm 5.9 \%$, as the flow rate increased from 100 to $500 \mu \mathrm{L} / \mathrm{min}$. The increase in the passage of RBCs could be due to high flow rates that exert more shear stress on cells and subsequently force RBCs through the filter pores. The passage rates of blood components are summarized in Table 1. As shown in Figure 4 and Table 1, the evaluated flow rates did not significantly affect the passage rates of blood components, which leads to the conclusion that the flow rate of manual pipetting (within the evaluated flow-rate range) can be used for plasma separation and virus isolation without using a micropump.

Lastly, we assessed HIV recovery on-chip by employing 1 and $2 \mu \mathrm{m}$ pore-sized filters by manual pipette-based, pump-free separation (Figure 5). To prepare HIV samples, we spiked three concentrations $\left(10^{3}, 10^{4}\right.$, and $10^{5}$ RNA copies $/ \mathrm{mL}$ ) of HIV into whole blood, because current clinical practice recommends 1000-10,000 RNA copies/mL to monitor antiretroviral treatment in resource-constrained settings. ${ }^{35-37}$ The measured HIV concentrations in the control (without on-chip filtration) were 624, 12,873, and 114,390 copies/mL. The measured HIV concentrations after filtration using microchips of $1-\mu \mathrm{m}$ pore size were 456, 9280 , and 85,173 copies $/ \mathrm{mL}$, leading to recovery rates of $74.5 \% \pm 2.4 \%, 72.1 \% \pm 2.4 \%$, and $73.1 \% \pm 2.4 \%$, respectively (Figure 5A). For the $2 \mu \mathrm{m}$ pore-size microchip, measured HIV concentrations after filtration were $488,10,358$, and 102,840 copies $/ \mathrm{mL}$, leading to recovery rates of $89.9 \% \pm 5.0 \%, 80.5 \% \pm 4.3 \%$, and $78.2 \% \pm 3.8 \%$, respectively (Figure 5A). These data demonstrate that the presented device can be potentially used for clinical testing. Statistical analysis revealed that $2 \mu \mathrm{m}$ pore-sized microchips had a higher recovery of HIV viruses than $1 \mu \mathrm{m}$ pore-sized microchips only at 1000 copies $/ \mathrm{mL}(P<0.05)$. In addition, we evaluated our devices using anonymous discarded HIV-infected patient blood samples (Figure 5B). The results showed that $1 \mu \mathrm{m}$ pore-sized filters had a recovery ranging from $74.2 \% \pm 7.3 \%$ to $84.6 \% \pm 4.7 \%$, and $2 \mu \mathrm{m}$ poresized filters had a recovery ranging from $73.1 \% \pm 8.3 \%$ to $82.5 \% \pm 4.1 \%$. One-way analysis of variance showed that there was no statistical significance in HIV recovery between these two microchips.

The significant difference in HIV recovery at 1000 copies/mL may be attributed to variations in RTPCR at such a low input of HIV RNA in the reaction. At 1000 copies $/ \mathrm{mL}$ of HIV spiked in whole blood, loading of $40 \mu \mathrm{L}$ blood only led to 40 copies of HIV particles in the inlet chamber. Assuming 100\% recovery of virus isolation and RNA extraction, $7.5 \mu \mathrm{L}$ of RNA out of $50 \mu \mathrm{L}$ extract in RT resulted in six copies of HIV cDNA (twelve copies of LTR DNA), which were further split into two reactions of PCR. In this case, only six copies of HIV LTR were amplified in PCR, which may have led to the difference in HIV recovery at 1000 copies $/ \mathrm{mL}$ (Figure 5A). By contrast, there was no significant difference in HIV recovery at 
A

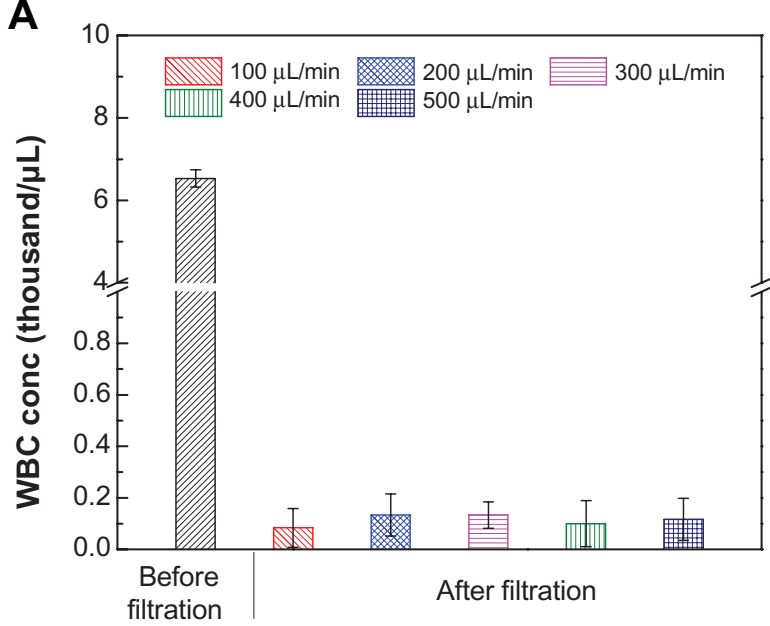

C

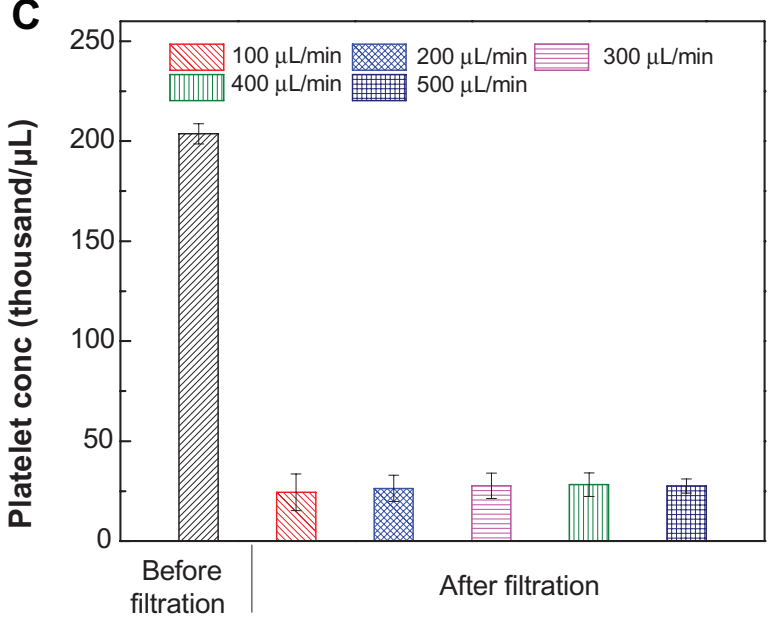

B

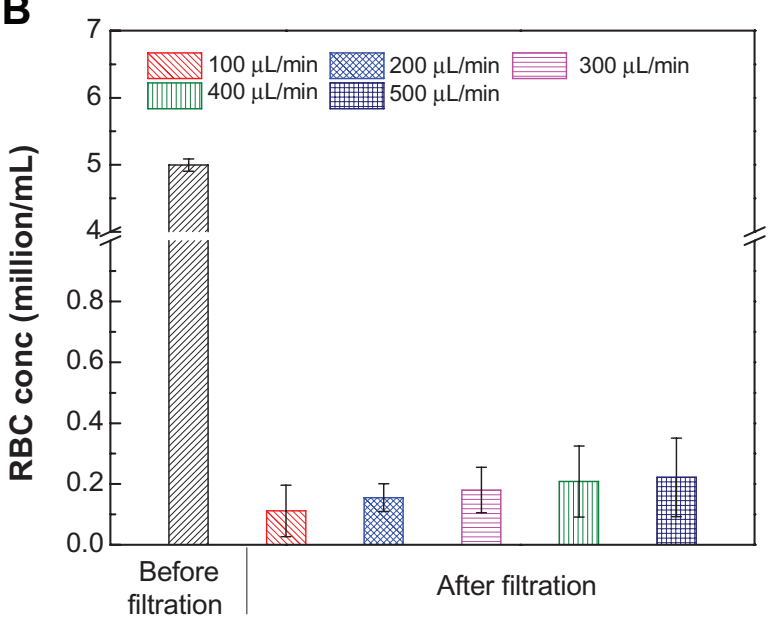

D

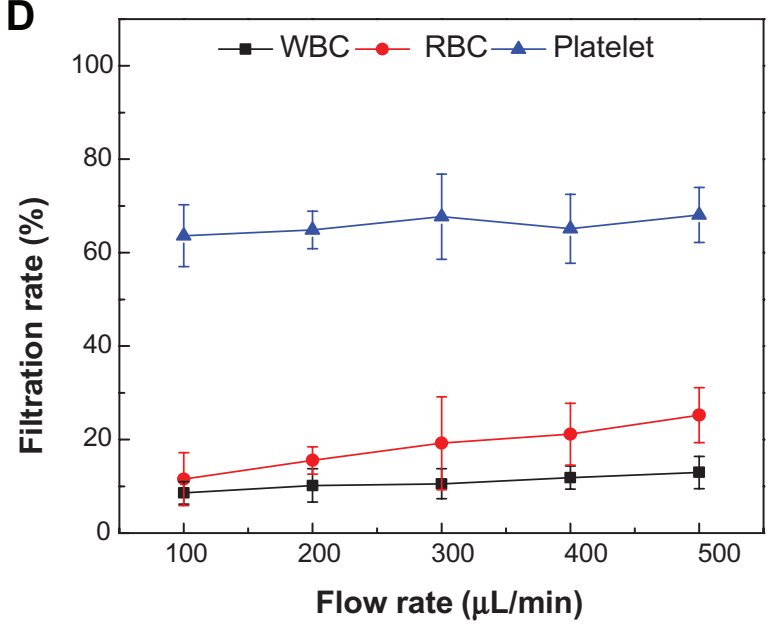

Figure 4 (A-D) Passage rates of blood components on-chip at different flow rates. $40 \mu \mathrm{L}$ of blood was injected into the size-based microchips with a pore size of $2 \mu \mathrm{m}$ at a flow rate ranging from 100 to $500 \mu \mathrm{L} /$ minute. The device was injected with $300 \mu \mathrm{L}$ of PBS to evaluate the passage rate. The collected filtrate volume was $202 \pm 2 \mu \mathrm{L}$. Comparisons of the concentrations of blood components including RBCs (A), WBCs (B), and platelets (C). The passage rates of RBCs, WBCs and platelets were also compared (D). Note: Data are presented as average \pm standard error $(n=6)$.

Abbreviations: WBCs, white blood cells; RBCs, red blood cells.

higher concentrations. Nevertheless, we cannot exclude the possibility that $2 \mu \mathrm{m}$ pore-sized microchips may allow more free viruses to pass through, since $1 \mu \mathrm{m}$ pore-sized microchips resulted in relatively lower volumes of filtrate. The $2 \mu \mathrm{m}$ pore-sized microchips left $0.13 \times 10^{3}$ cells $/ \mu \mathrm{L}$ of WBCs (Figure 2) in the filtrate, compared to a standard centrifugation protocol (1000 $\mathrm{g}$, twice for 10 minutes), which removed nearly $100 \%$ of blood cells.

In this study, we demonstrated successful and reliable recovery of HIV particles from whole blood using a filter-based microchip without requiring a micropump. The presented filter microchip can be used to separate plasma for POC testing, including initial sample processing in a microfluidic-based ELISA or PCR virus-detection system. Generally, plasma samples, rather than whole blood, are needed in PCR and ELISA for optimal results. As such, microfluidic-based isolation of plasma samples would facilitate POC testing when integrated with microchip-based immunoassay and nucleic acid amplification, ${ }^{5,38-40}$ as well as sensing technologies such as surface plasmon resonance, ${ }^{16}$ photonic crystal-based sensors, ${ }^{17}$ and spectral reflectance imaging biosensors. ${ }^{41}$ The example that we demonstrated was virus isolation on-chip, which can facilitate HIV viral load testing in resource-constrained settings since the viral load is defined as the free circulating viruses in plasma. The microchip platform can also be modified to provide sample processing for a host of other applications. Since the virus size is below $1 \mu \mathrm{m}$, the developed filter microchip, in principle, can be used as a generic virus-filtration device. Another potential application is that the device may be adapted for 
Table I Effects of device operation parameters on the passage rate of blood components

\begin{tabular}{cccr}
\hline \multicolumn{5}{c}{ Passage rate $(\%)$} \\
\cline { 2 - 4 } & White blood cells & Red blood cells & Platelets \\
\hline Pore size $(\mu \mathrm{m})$ & & \\
0.4 & $1.4 \pm 0.3$ & $0.3 \pm 0.1$ & $2.1 \pm 0.2$ \\
1 & $3.1 \pm 1.3$ & $1.8 \pm 0.2$ & $47.7 \pm 3.6$ \\
2 & $10.5 \pm 4.2$ & $18.3 \pm 18.3$ & $67.7 \pm 5.3$ \\
3 & $25.1 \pm 11.5$ & $49.7 \pm 16.0$ & $74.6 \pm 9.1$ \\
Flow rate $(\mu \mathrm{L} / \mathrm{min})$ & & \\
100 & $8.6 \pm 2.4$ & $11.5 \pm 5.7$ & $63.6 \pm 6.6$ \\
200 & $10.2 \pm 3.6$ & $15.5 \pm 2.9$ & $64.9 \pm 4.0$ \\
300 & $10.5 \pm 3.2$ & $19.2 \pm 9.9$ & $67.7 \pm 9.1$ \\
400 & $11.8 \pm 2.5$ & $21.1 \pm 6.6$ & $65.1 \pm 7.4$ \\
500 & $12.9 \pm 3.5$ & $25.2 \pm 5.9$ & $68.1 \pm 5.9$ \\
Wash volume $(\mu \mathrm{L})$ & & \\
200 & $2.0 \pm 1.4$ & $4.6 \pm 1.2$ & $30.0 \pm 1.0$ \\
300 & $10.5 \pm 4.2$ & $19.2 \pm 16.9$ & $67.7 \pm 9.1$ \\
400 & $11.7 \pm 3.9$ & $19.7 \pm 13.5$ & $72.7 \pm 3.3$ \\
500 & $10.3 \pm 3.2$ & $29.0 \pm 2.6$ & $76.6 \pm 6.6$ \\
\hline
\end{tabular}

Notes: For pore-size evaluation, a flow rate of $300 \mu \mathrm{L} /$ minute and a wash volume of $300 \mu \mathrm{L}$ were used. For flow-rate evaluation, a pore size of $2 \mu \mathrm{m}$ and a wash volume of $300 \mu \mathrm{L}$ were used. For wash-volume evaluation, a pore size of $2 \mu \mathrm{m}$ and a flow rate of $300 \mu \mathrm{L} / \mathrm{min}$ were used. Data are presented as average \pm standard error $(n=6)$.

filtration of mycobacterium TB, which is approximately $2-4 \mu \mathrm{m}$ in length and $0.2-0.5 \mu \mathrm{m}$ in width. This application may require pore sizes as large as $4 \mu \mathrm{m}$ of efficient separation for mycobacterium TB, since sputum may clog the filter easily due to viscosity.

A

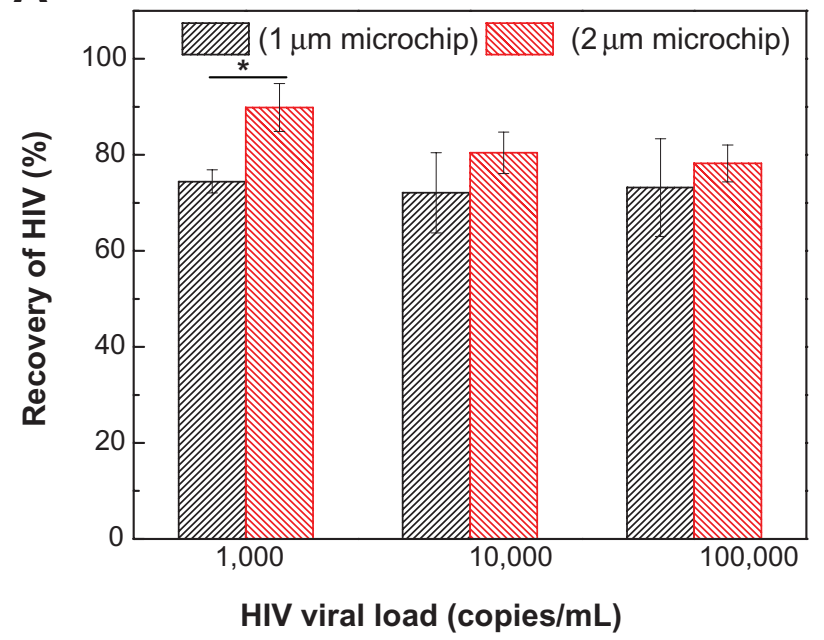

An apparent advantage of the filter microchip is that the used materials (10 $\notin$ on PMMA, and $67 \notin$ on filter membrane) significantly reduce the cost associated with plasma separation in a laboratory setting (consumables and a centrifuge). The filter device was designed to be disposable and inexpensive, thus avoiding contamination between samples. In addition, there is no involvement of antibodies or nucleic acids in the microchip that could degrade with heat or humidity. Thus, the device can be robust at various temperature and humidity conditions. Although hand-cranked centrifuges can be potentially used to provide the required centrifugal forces for plasma separation, they require an operator to continuously crank the centrifuge over a period of time (eg, 10 minutes), which is tedious and may lead to operator-to-operator variations. There have also been efforts to use an eggbeater to separate plasma from blood. ${ }^{42}$ However, manual centrifugation requires more hands-on time, and this process cannot be readily integrated with on-chip analytical systems. In comparison, the filter microchip only takes a minute to complete the plasma/virus separation, significantly decreasing the turnaround time. Another potential solution to plasma separation at the POC might be to place a filter in a pipette tip. However, the effective filtering area can be considerably limited by the size of pipette tips, which may result in low yields in plasma separation. In addition, fixing the filter in the pipette tips may be technically difficult, and it would be difficult to control the flow, thus causing variations from operator to operator.

B

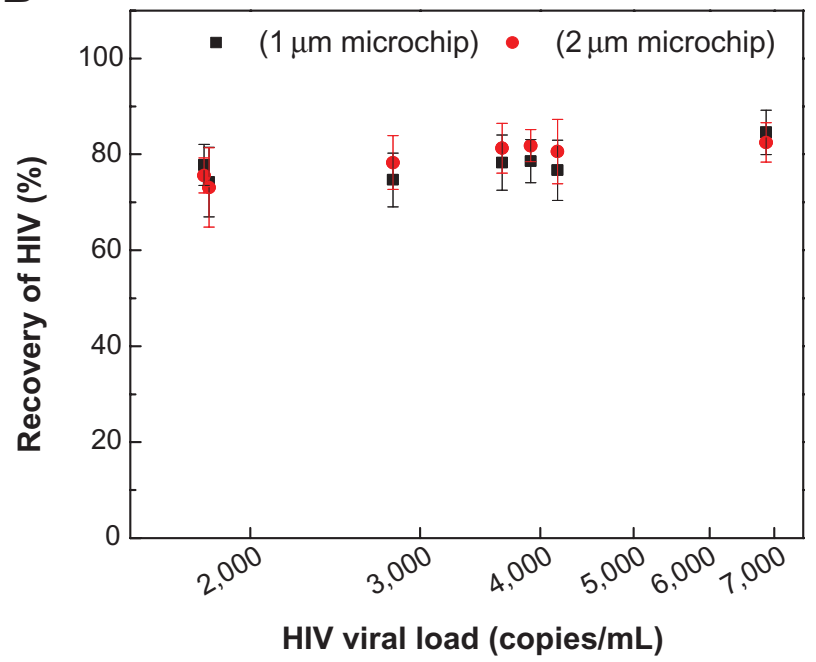

Figure 5 (A and B) Manual pipette-based, pump-free separation of HIV particles from whole blood using the filter microchip. (A) Whole blood samples spiked with HIV at concentrations of $10^{3}, 10^{4}$, and $10^{5}$ copies $/ \mathrm{mL}$, and (B) discarded HIV patient whole blood samples were flowed through filter microchips with membrane pore size of I $\mu \mathrm{m}$ or $2 \mu \mathrm{m}$.

Notes: Subsequently, blood samples containing HIV particles were manually washed with $300 \mu \mathrm{L}$ of phosphate-buffered saline and all the filtrate (approximately $200 \mu \mathrm{L}$ ) was collected. HIV recoveries (\%) in both I $\mu \mathrm{m}$ and $2 \mu \mathrm{m}$ filter microchips were then calculated using formula 2 . Data are presented as average \pm standard error $(\mathrm{n}=6)$. One-way analysis of variance was performed. $* P<0.05$; in $\mathrm{B}, \mathrm{x}$-axis is log-scaled. 


\section{Conclusion}

In conclusion, we developed a disposable, pump-free, size exclusion-based filter microchip that can be used for plasma and virus separation from unprocessed whole blood samples in resource-constrained settings. Initially, we evaluated the microchip at various flow rates and showed that the flow rate does not affect the HIV recovery rates from whole blood. These evaluated flow rates overlap with range of manual pipetting. Then, we demonstrated that the microchip produces high yields of separated HIV particles and plasma using only manual pipetting, eliminating the complexity of using a micropump. Due to its simplicity, this microfluidic device can be potentially integrated with HIV microchip diagnostic systems, on-chip ELISA and PCR sensing methodologies, and optical detection modalities, thus realizing comprehensive sample-to-result testing. This would eliminate the need for peripheral instruments for plasma separation. Since the pore size of the filter is adjustable, the microchip could be broadly adapted for applications targeting other pathogens, including viruses such as influenza, allowing rapid sample processing and blood screening at the POC.

\section{Acknowledgments}

We would like to acknowledge NIH R01 A1081534, NIH R01A1093282, R21 AI087107, NIH U54EB015408, and R21 HL095960. Also, this work was made possible by a research grant that was awarded and administered by the United States Army Medical Research and Materiel Command (USAM$\mathrm{RMC}$ ) and the Telemedicine and Advanced Technology Research Center (TATRC), at Fort Detrick, MD.

\section{Disclosure}

The authors report no conflicts of interest in this work.

\section{References}

1. Joint United Nations Programme on HIV/AIDS (UNAIDS). UNAIDS Report on the Global AIDS Epidemic 2010.2010. Available from: http:// www.unaids.org/documents/20101123_GlobalReport_em.pdf. Accessed July 18, 2012.

2. Vijaykrishna D, Poon LL, Zhu HC, et al. Reassortment of pandemic H1N1/2009 influenza A virus in swine. Science. 2010;328:1529.

3. Cohen J. Swine flu pandemic. What's old is new: 1918 virus matches 2009 H1N1 strain. Science. 2010;327:1563-1564.

4. Moon S, Gurkan UA, Blander J, et al. Enumeration of CD4+ T-cells using a portable microchip count platform in Tanzanian HIV-infected patients. PLoS One. 2011;6:e21409.

5. Wang S, Zhao X, Khimji I, et al. Integration of cell phone imaging with microchip ELISA to detect ovarian cancer HE4 biomarker in urine at the point-of-care. Lab Chip. 2011;11:3411-3418.

6. Gurkan UA, Anand T, Tas H, et al. Controlled viable release of selectively captured label-free cells in microchannels. Lab Chip. 2011;11(23):3979-3989.
7. Alyassin MA, Moon S, Keles HO, et al. Rapid automated cell quantification on HIV microfluidic devices. Lab Chip. 2009;9:3364-3369.

8. Bhattacharyya A, Klapperich CA. Microfluidics-based extraction of viral RNA from infected mammalian cells for disposable molecular diagnostics. Sens Actuators B Chem. 2008;129:693-698.

9. Bhattacharyya A, Klapperich CM. Thermoplastic microfluidic device for on-chip purification of nucleic acids for disposable diagnostics. Anal Chem. 2006;78:788-792.

10. Al-Soud WA, Radstrom P. Purification and characterization of PCR-inhibitory components in blood cells. J Clin Microbiol. 2001;39:485-493.

11. Chakravarti A, Rawat D, Yadav S. Whole blood samples as an alternative to serum for detection of immunity to measles virus by ELISA. Diagn Microbiol Infect Dis. 2003;47:563-567.

12. Raivio T, Korponay-Szabó IR, Paajanen T, et al. Comparison of a novel whole blood transglutaminase-based ELISA with a whole blood rapid antibody test and established conventional serological celiac disease assays. J Pediatr Gastroenterol Nutr. 2008;47:562-567.

13. Wang S, Esfahani M, Gurkan UA, Inci F, Kuritzkes DR, Demirci U. Efficient on-chip isolation of HIV subtypes. Lab Chip. 2012;12:1508-1515.

14. Kim YG, Moon S, Kuritzkes DR, Demirci U. Quantum dot-based HIV capture and imaging in a microfluidic channel. Biosens Bioelectron. 2009;25:253-258

15. Santiago-Cordoba MA, Boriskina SV, Vollmer F, Demirel MC. Nanoparticle-based protein detection by optical shift of a resonant microcavity. Appl Phys Lett. 2011;99:073701.

16. Trevino J, Calle A, Rodriguez-Frade JM, Mellado M, Lechuga LM. Surface plasmon resonance immunoassay analysis of pituitary hormones in urine and serum samples. Clin Chim Acta. 2009;403:56-62.

17. Kim SM, Zhang W, Cunningham BT. Photonic crystals with $\mathrm{SiO}_{2}-\mathrm{Ag}$ "post-cap" nanostructure coatings for surface enhanced Raman spectroscopy. Appl Phys Lett. 2008;93:143112.

18. Gurkan UA, Moon S, Geckil H, et al. Miniaturized lensless imaging systems for cell and microorganism visualization in point-of-care testing. Biotechnol J. 2011;6:138-149.

19. Lee WG, Kim YG, Chung BG, Demirci U, Khademhosseini A. Nano/microfluidics for diagnosis of infectious diseases in developing countries. Adv Drug Deliv Rev. 2010;62:449-457.

20. Wang S, Xu F, Demirci U. Advances in developing HIV-1 viral load assays for resource-limited settings. Biotechnol Adv. 2010;28:770-781.

21. Zhang JL, Guo QQ, Liu M, Yang J. A lab-on-CD prototype for highspeed blood separation. J Micromech Microeng. 2008;18:125025.

22. Li TJ, Zhang LM, Leung KM, Yang J. Out-of-plane microvalves for whole blood separation on lab-on-a-CD. J Micromech Microeng. 2010;20:105024

23. Walker GM, Beebe DJ. A passive pumping method for microfluidic devices. Lab Chip. 2002;2:131-134.

24. Yang S, Undar A, Zahn JD. A microfluidic device for continuous, real time blood plasma separation. Lab Chip. 2006;6:871-880.

25. Dimov IK, Basabe-Desmonts L, Garcia-Cordero JL, Ross BM, Ricco AJ, Lee LP. Stand-alone self-powered integrated microfluidic blood analysis system (SIMBAS). Lab Chip. 2011;11:845-850.

26. Qin L, Vermesh O, Shi Q, Heath JR. Self-powered microfluidic chips for multiplexed protein assays from whole blood. Lab Chip. 2009;9:2016-2020.

27. Yager P, Domingo GJ, Gerdes J. Point-of-care diagnostics for global health. Annu Rev Biomed Eng. 2008;10:107-144.

28. Thorslund S, Klett O, Nikolajeff F, Markides K, Bergquist J. A hybrid poly(dimethylsiloxane) microsystem for on-chip whole blood filtration optimized for steroid screening. Biomed Microdevices. 2006;8:73-79.

29. Gentile M, Adrian T, Scheidler A, et al. Determination of the size of HIV using adenovirus type 2 as an internal length marker. JVirol Methods. 1994;48:43-52. 
30. Moon S, Keles HO, Ozcan A, et al. Integrating microfluidics and lensless imaging for point-of-care testing. Biosens Bioelectron. 2009;24:3208-3214.

31. Wang S, Inci F, Chaunzwa TL, et al. Portable microfluidic chip for detection of Escherichia coli in produce and blood. Int J Nanomedicine. 2012;7:2591-2600.

32. Candotti D, Temple J, Owusu-Ofori S, Allain JP. Multiplex realtime quantitative RT-PCR assay for hepatitis B virus, hepatitis C virus, and human immunodeficiency virus type 1. J Virol Methods. 2004;118:39-47.

33. Young B, Lowe J, Stevens A, Heath JW. Wheater's Functional Histology: A Text and Color Atlas. 5th ed. Edinburgh: Churchill Livingstone; 2006.

34. Park Y, Best CA, Auth T, et al. Metabolic remodeling of the human red blood cell membrane. Proc Natl Acad Sci U SA. 2010;107:1289-1294

35. Stevens WS, Scott LE, Crowe SM. Quantifying HIV for monitoring antiretroviral therapy in resource-poor settings. J Infect Dis. 2010; 201 Suppl 1:S16-S26.

36. Tanriverdi S, Chen L, Chen S. A rapid and automated sample-to-result HIV load test for near-patient application. J Infect Dis. 2010;201 Suppl 1: S52-S58.
37. Usdin M, Guillerm M, Calmy A. Patient needs and point-of-care requirements for HIV load testing in resource-limited settings. J Infect Dis. 2010;201 Suppl 1:S73-S77.

38. Hosokawa K, Omata M, Maeda M. Immunoassay on a power-free microchip with laminar flow-assisted dendritic amplification. Anal Chem. 2007;79:6000-6004.

39. LaBarre P, Hawkins KR, Gerlach J, et al. A simple, inexpensive device for nucleic acid amplification without electricity-toward instrumentfree molecular diagnostics in low-resource settings. PLoS One. 2011;6:e19738.

40. Liu C, Qiu X, Ongagna S, et al. A timer-actuated immunoassay cassette for detecting molecular markers in oral fluids. Lab Chip. 2009;9:768-776.

41. Daaboul GG, Vedula RS, Ahn S, et al. LED-based interferometric reflectance imaging sensor for quantitative dynamic monitoring of biomolecular interactions. Biosens Bioelectron. 2011;26:2221-2227.

42. Wong AP, Gupta M, Shevkoplyas SS, Whitesides GM. Egg beater as centrifuge: isolating human blood plasma from whole blood in resourcepoor settings. Lab Chip. 2008;8:2032-2037.
International Journal of Nanomedicine

\section{Publish your work in this journal}

The International Journal of Nanomedicine is an international, peerreviewed journal focusing on the application of nanotechnology in diagnostics, therapeutics, and drug delivery systems throughout the biomedical field. This journal is indexed on PubMed Central, MedLine, CAS, SciSearch $\AA$, Current Contents ${ }^{\circledR} /$ Clinical Medicine,

\section{Dovepress}

Journal Citation Reports/Science Edition, EMBase, Scopus and the Elsevier Bibliographic databases. The manuscript management system is completely online and includes a very quick and fair peer-review system, which is all easy to use. Visit http://www.dovepress.com/ testimonials.php to read real quotes from published authors. 